\title{
Plant biotechnology and food security in Latin America and the Caribbean
}

\author{
Juan Izquierdo* \\ FAO Regional Office for Latin America and the Caribbean \\ REDBIO/FAO-Technical Co-operation Network on Plant Biotechnology \\ for Latin America and the Caribbean \\ P.O. Box 10095, Santiago, Chile \\ E-mail: juan.izquierdo@fao.org \\ Gustavo A. de la Riva \\ Centre of Genetic Engineering and Biotechnology, Havana, Cuba \\ Paper based on the keynote presented by the main author to the III Latin American Meeting on Plant Biotechnology
} (REDBIO'98), 1-15 June 1998, Havana Cuba

Keywords: Andean crops, Food security, Institutional development, Plant biotechnology, Plant genetic engineering, REDBIO network, Sustainable crop production.

Agriculture is expected to feed an increasing population, forecasted to reach 8billion by 2020 , out of whom 6.7 billion will be in developing countries where the carrying capacity of agricultural lands will soon be reached. In Latin American and the Caribbean (LAC) countries, in spite of the abundance of natural resources and continued investments in development, poverty and food insecurity affect more than 55 percent of the rural population. Fifteen years ago, plant biotechnology comprised only a few applications of tissue culture, recombinant DNA technology and monoclonal antibodies. Today, genetic transformation, and markeraided selection and breeding are just a few of the examples of the applications in crop improvement with profound implications for the LAC Region. Plant biotechnology applications must respond to increasing demands in terms of food security, socio-economic development and promote the conservation, diversification and sustainable use of plant genetic resources as basic inputs for the future agriculture of the Region. Food security is defined by FAO as the access by all people at all times to the food needed for a healthy and active life. The concept means the achievement of the food self-sufficiency, and guarantees that this condition will be sustained in the future. Food security implies reaching productive growth and the preservation of the environment. Malnutrition affects $15 \%$ the population in Mexico, Central America and the Caribbean and $13 \%$ of the population in South America, while the Region represents nearly 23\% of the arable lands and $12 \%$ of the world cultivated areas. Plant biotechnology offers several possibilities for increasing productivity, diversification and production, while developing a more sustainable agriculture. It includes biopesticide production, plant tissue culture techniques, and the use of advanced molecular biology techniques for plant transformation, genomic analysis coupled with breeding and plant-disease diagnoses. Agricultural biotechnology in the LAC Region is characterised by a repetitive and academic model, where many of the project objectives do not respond to the real needs of crop production and food security in the Region. Many small research teams in universities or agricultural institutions, poorly connected and/or integrated, have a high dispersion of facilities and qualified labor force. The database of REDBIO/FAO in 1999, register 539 laboratories affiliated in 23 countries of the Region. $83 \%$ of the member laboratories have less than 10 researchers and technical personnel and only $72 \%$ of them have three postgraduates or more. The majority of these small research groups lack adequate technology and properly trained personnel to start relevant projects, attractive for public and private investment. Public and private institutions should play a key role to create or strengthen National Programmes to guide efforts toward the real production needs and food security. National Programs should identify objectives and priorities in each country, in order to promote regional collaboration, find financial support and facilitate the transfer of appropriate biotechnology and biosafety norms to the producers by promoting the application of valid results.

Agriculture is expected to feed an increasing population, forecasted to reach 8 billion by 2020, out of whom 6.7 billion will be in developing countries where the carrying capacity of agricultural lands will soon be reached given the current technology and the on-going environmental degradation (FAO, 1999). New technologies, if properly focused, offer a responsible way to enhance agricultural productivity at present and for the future. As suggested by the Nobel Peace Laureate, Norman Bourlag (1997), biotechnology and genetic plant engineering, 
complemented with conventional plant breeding, are needed to boost crop yields to feed the world. Today, nearly 800 million people suffer from malnutrition; 1100 millions do not receive appropriate nutrition while subsisting below the levels of poverty (FAO, 1996a). In the case of the Latin American and the Caribbean (LAC) countries, in spite of the abundance of natural resources and continued investments in development, rural poverty and food insecurity have persistently affected more than 55 percent of the rural population with one third of the latter being below the extreme poverty line (income below a basic food basket). Furthermore, in six out of eleven countries for which there was information for several years, extreme poverty increased between the beginning of the eighties and the mid nineties. These elements establish the magnitude of the poverty and food insecurity to which research in agricultural production, comprising the application and complement of plant biotechnology, has to find a way to alleviate.

The food sector in the LAC Region is characterised, among other factors, by the growing dependence on food imports, primarily cereals, the decelerated growth of the agricultural production and poverty affecting wide sectors especially the rural population. Within this context, the increasing frequency of adverse environmental and climatic factors as drought and desertification, soil erosion, floods and hurricanes, and on-going changes in land use regarding other economic activities, are producing a significant reduction of the agricultural areas (James, 1996, 1997). Under these conditions, the use of sustainable technologies, traditional or modern, focusing on those with less input demands as well as emphasis on product quality and productivity are important factors for employment and income generation.

Fifteen years ago, plant biotechnology comprised only a few applications of tissue culture, recombinant DNA technology and monoclonal antibodies. Today, genetic transformation, and marker-aided selection and breeding are just a few examples of applications in crop improvement with profound implications for the LAC Region (Izquierdo, 1999). Plant biotechnology applications must respond to increasing demands in terms of food security, socio-economic development and promote the conservation, diversification and sustainable use of plant genetic resources as basic inputs for the future agriculture of the Region (FAO, 1999).

The scientific results obtained in the last two decades substantiate biotechnology as an option to increase food production. Some of the imperative reasons to use new biotechnology in an upward form reside in the fact that the benefits of the Green Revolution have already been surpassed and cannot guarantee the success of sustained food programs including their inability in terms of economic and environmental costs. Although the objective of the Green Revolution was to promote the production and the trade of cereals and other agricultural commodities, the majority of the developing countries have become net importers of basic cereal foods for daily human consumption and for livestock feeding (FAO, 1996b; Rosendal, 1992; Asiema, 1994).

The LAC agricultural sector needs a strong input of new knowledge and technologies to successfully confront the food insecurity challenge coupled with a realistic interpretation of the global environmental and economic situation (Commandeur, 1994; Vunne, 1995). It is in this complex food security context where biotechnology is called to play a growing role to contribute toward a safer world.

\section{The food security concept}

Food security is defined by FAO as the access by all people at all times to the food needed for a healthy and active life. The concept means the achievement of the food selfsufficiency, and guarantees that this condition will be sustained in the future. Food security also implies reaching a productive growth, compatible with the economic status of the producers and the preservation of the environment. The factors that determine the degree of food security, in any Region, country or zone in particular, are food availability, production stability and access to food by all members of the community (FAO, 1998).

Food availability is a factor directly related to the productivity of raw food supplies, as grains, root and tubers, oil and molasses. Variations in yield due to limitations of the crop genetic potential for a given environment and losses due to biotic, abiotic and postharvest factors, greatly affects this issue.

Stability is related to the conditions of the productive process, including the sustained handling of natural resources, an appropriate policy for environmental protection, and the creation of an adequate rural infrastructure and political dynamics of rural development.

Access to food is a factor directly related to the prevailing socio-economic conditions in a particular zone or country. The lack of access to food is often exacerbated by the fact that producers try to keep higher prices by destroying large amounts of stocked foods or livestock. In addition, some countries that generate food surplus deny their access to others countries as a measure of political pressure. The causes and consequences of food insecurity and poverty are inextricably linked (FAO, http://www.fao.org/spfs/ ).

The per capita world food supply was equivalent to 2300 daily calories as an average in 1970. This figure included data from developed countries, whose average was of 3030 calories, as well as those from developing countries, where this indicator hardly reached to 1960 calories per capita, showing the enormous disproportion existing between both groups. $75 \%$ of the population of the developing countries, around 1600 million, corresponds to countries whose daily 
average per capita was nearly 1850 calories. The situation is even more precariou s for the poorest sectors in the population due to the existing inequalities in each country (FAO, 1996c; Garett, 1997).

Chronic undernutrition and food insecurity are principally caused by: low productivity in agriculture, frequently caused in part by policy, institutional and technological constraints; high seasonal and year-to-year variability in food supplies, often the result of unreliable rainfall and insufficient water for crop and livestock production; lack of off-farm employment opportunities, contributing to low and uncertain incomes in urban and rural areas.

\section{Food security in the Latin American and Caribbean Region}

According to the countries' technical documents prepared for the Food World Summit, in the decade of the 70 the per capita food supply in the Region increased from 2360 to 2510 calories, while in the world it varied from 2300 to 2440 calories, compared with a global increase from 1960 to 2130 calories in the developing countries altogether (FAO, 1996a, b and c). This growing tendency was observed until the decade of the 80 when the per capita daily food supply went up to 2720 calories for the LAC Region, 2330 for the developing countries and 2580 for the world.

Unfortunately, these indexes did not represent a significant improvement in food security and remained practically unaltered (14\% in 1980 and $15 \%$ in 1992 Considering the growth of the LAC population (279 million in 1970, 354 million in 1980, 443 million in 1992, 593 million estimated for 2010) malnutrition embraced 53 million people in 1970 , 48 million in 1980 and 64 million in 1992. Today, it affects $15 \%$ of the population in Mexico, Central America and the Caribbean and $13 \%$ of the population in South America (FAO, 1996c and d) while the Region represents nearly $23 \%$ of the arable lands, $12 \%$ of the world cultivated areas, $46 \%$ of the forests, $31 \%$ of the world's fresh water reserves, and a rich ecosystem, with $50 \%$ of the plant and animal species of the biosphere representing an immense wealth in genetic resources.

Within the above context, food production growth should be sustained as a guarantee of food security (FAO, 1996a; Trigo, 1995) considering the differences among the LAC Region countries and internally among the different social sectors. This inequality is increasing and a society under such conditions cannot have food security. The levels of food security in the LAC Region have not increased and this situation should be reverted without delay.

To improve the levels of food security in countries with low income and food deficit, FAO has implemented the Special Program for Food Security (SPFS) as an assistance program to increase the food production and productivity on those countries less able to meet their food needs with imports (Figure 1).

\section{Low-Income Food-Deficit Countries (as of March 1998)}

\begin{abstract}
At present, 83 nations are defined as low-income food-deficit countries (LIFDCs) -42 in Africa, 24 in Asia, 7 in Latin America and the Caribbean, 7 in Oceania and 3 in Europe. These countries are home to the vast majority of the world's 800
\end{abstract}

million chronically undernourished people. Many LIFDCs, particularly in Africa, do not grow enough food to meet all their needs and lack sufficient foreign exchange to fill the gap by purchasing food on the international market.

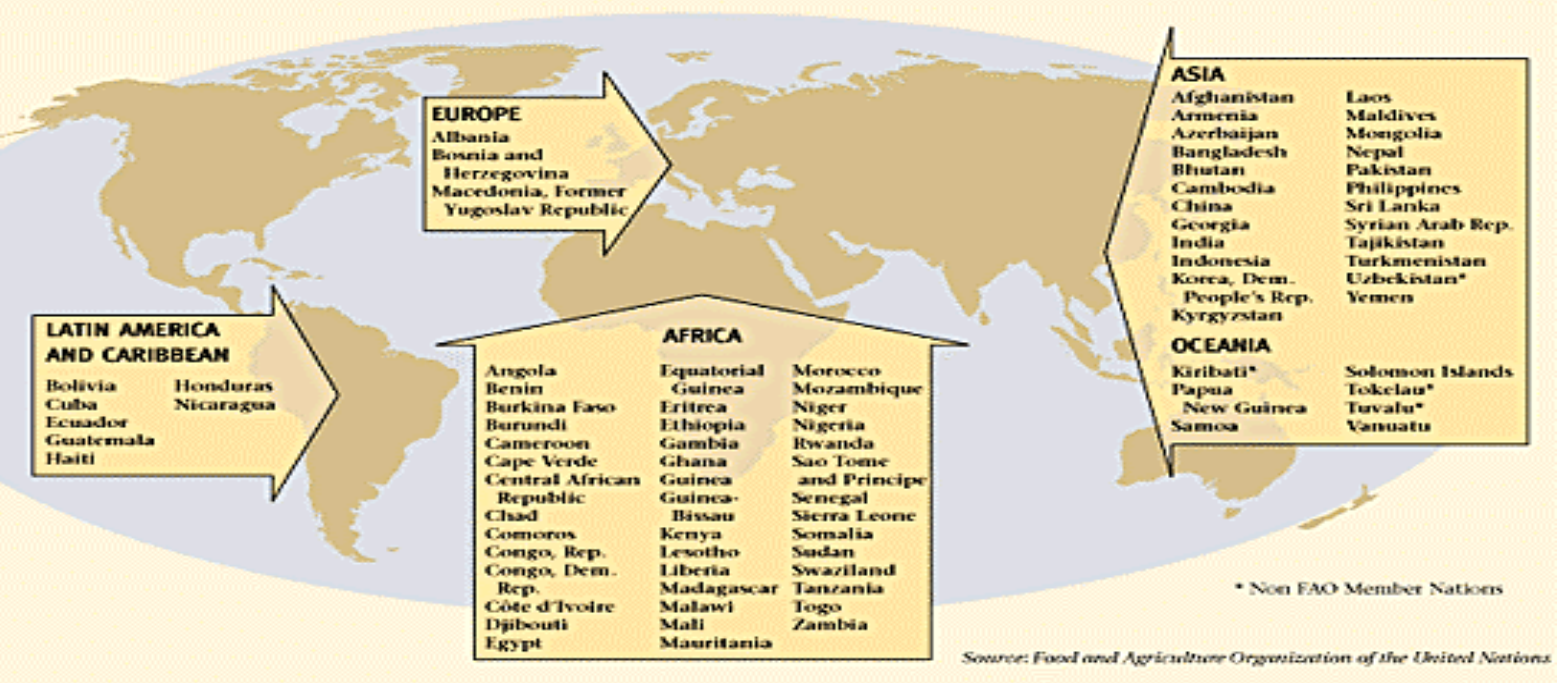

Figure 1. Low-income and food-deficit countries, according to FAO. 
The objective is to reduce the present number of malnourished people in the world to one half, by the year 2015. Although in many of the LAC countries the demographic pressure is less than in other developing regions due to lower birth rate and better educational and health facilities (James, 1996; FAO, 1996; Garett, 1997; Trigo, 1995), a strong revitalisation of the agricultural sector is needed to secure food and rural income.

Agriculture is a fundamental sector for the establishment of an appropriate food production system. It has a marked multiplier effect in the general economic growth, generating employment and involving, besides its own activities, important economic sectors like transport, storage, processing and trade. The sector demands additional services beyond those already mentioned. Consequently, appropriate agricultural development can generate increased food availability, improving social development and providing better access to food.

\section{Biotechnology and agriculture}

Plant biotechnology offers several possibilities for increasing productivity, diversification and production, while developing a more sustainable agriculture (Izquierdo, 1999). This technology includes biopesticide production, plant tissue culture techniques, and the use of advanced molecular biology techniques for plant transformation, genomic analysis coupled with breeding and plant-disease diagnoses. It can be an effective instrument to mitigate the consequences of climatic change and can offer cropping alternatives in lands degraded by erosion and desertification or by careless agricultural use (FAO, 1999). Agricultural biotechnology has different levels of implementation and development according to its degree of complexity, infrastructure costs and investment.

The first level includes technologies of low complexity and cost like handmade and semi-industrial production of biological products, like bio-inoculants for leguminous crops, reproduction of pest antagonist and pest predators and production of bio-pesticides. The transfer of these simple technologies to the small producers has proven feasible and it can offer remarkable results quickly.

The second level comprises the application of cell and tissue culture techniques, cell culture for production of secondary metabolites, disease diagnostic systems based on polyclonal antibodies and other technologies with medium complexity. This stage can also include investments to implement semi-industrial production of biological products. The results of these technologies can be seen in the medium term (three to five years), depending of the complexity of the projects and the degree of organisation for extending the results to the field or laboratory.

The first two stages do not require many resources but an efficient organisation for the transfer of technology to extend the results to the producers in a brief period of time.
The third level considers the use of molecular biology, genetic engineering, large-scale industrial production of biological products and complex plant cell and tissue culture techniques like liquid-bioreactors. This level is characterised by its complexity and high costs of research and development. The short term impact of this advanced biotechnology is limited because, as in any novel technology, it needs a starting phase corresponding to the innovation of its own research methods, analytical techniques and a semi-industrial base to supply the needed inputs and equipment. To create such conditions it is compulsory to build a framework of institutional support by public and private investment sectors.

Basic knowledge on the complexity of the molecular organisation of living organisms and their interrelationships is far from ts complete elucidation and limits the number of characters that can be manipulated by genetic engineering. Identification techniques, isolation and characterisation of new genes to be transferred to different crops to produce genetically modified plants GMP) are subjected to constant research. Plant genetic engineering now permits manipulating monogenic characters while the productive characteristics of the crop species, of a quantitative nature result in the expression of multiple genes (polygenic). Often, one isolated gene does not have a great influence in the complete genome expression and this reinforces the importance of conventional plant breeding assisted by molecular markers (Robentson, 1989).

The above issues are related to proprietary rights and institutional capacity building. The right of farmers to freely reuse a genetically modified food crop variety to strengthen food security and the patenting and marketing of GMP'seeds, is under dispute.

Biotechnology has begun to have an economic impact in the productivity of crops and in the decrease of production costs. In 1996 in the United States 15 novel GMP products existed in the market whose initial sales totalled about 380 million dollars. It is considered that this emergent market will increase $20 \%$ annually during the next decade (Persley, 1997). In that year, GMP were planted for the first time in Latin America comprising commercial fields, among which are herbicide tolerant soybean and insect resistant corn and cotton (Woodson, 1997) introduced by transnational companies after a case-to-case approval by national authorities. In 1999, 39.9 million hectares were globally planted, 6.7 in Argentina alone (James, 1999), resulting in a $44 \%$ increase in the adoption of such a technology by the medium and large farms. The release of genetically modified organisms is a matter of growing concern and requires the evaluation of biological risks and their environmental and socio-economic impact together with appropriate technological packages (FAO, 1999).

\section{Agricultural biotechnology in the Region}

Agricultural biotechnology development in the LAC 
Region is characterised by a repetitive and academic model in where many of the project objectives do not respond to the real needs of crop production and food security in the Region. Frequently, research projects and laboratories repeat work that has already been conducted by advanced research groups of developed countries without any further innovation and with a low degree of scientific creativity. On consulting the 30 scientific publications with the highest impact on biotechnology, we find that only $2 \%$ of the published scientific articles were generated in laboratories of the Region (data from Current Contents, 1997 processed by authors).

The regional situation was surveyed in 1990 by the Technical Co-operation Network on Plant Biotechnology (REDBIO/FAO)

[ http://www.rlc.fao.org/redes/redbio/html/home.htm ], where $63.4 \%$ of the plant biotechnology activities were focused on tissue culture with the support of the private sector, $10.1 \%$ corresponded to projects on plant disease diagnoses while genetic engineering and functional genomic analysis represented 8.6 and $2.7 \%$ respectively. Optimistically, the survey allowed to calculate for the next decade an estimated growth of $22.6 \%$ in the genetic engineering activities and of $4.1 \%$ in genomic analysis (Izquierdo et al. 1995).

In 1997, another REDBIO survey revealed that tissue culture maintained its predominance with $51.7 \%$ due to its immediate application in agriculture. An interesting aspect found was the increase of project research on genomic analysis, although not at the same scientific level in all laboratories. This responds to the need to complement plant breeding projects assisted by molecular markers and to the difficulties found with somaclonal variation $(4.9 \%$ from an estimate of $12.6 \%$ ). The expected expansion in genetic engineering did not take place; in fact genetic engineering fell in its relative position from $8.6 \%$ in 1990 to $6.4 \%$ in 1997. This tendency is the result of the complexities of these techniques, the high cost and the already mentioned limitations of genetic engineering at present.

Many small research teams in universities or agricultural institutions, poorly connected and/or integrated, have a high dispersion of facilities and qualified labor force. According to the database of REDBIO/FAO in 1999, 539 laboratories are affiliated in 23 countries of the Region. $83 \%$ of the member laboratories have less than 10 researchers and technical personnel and only $72 \%$ of them have three postgraduates or more. These small research groups lack adequate technology and trained human resources to start relevant projects attractive for public and private investment. This situation reduces opportunities for the development of projects on plant biotechnology with a significative impact on crop production or food security. In spite of this, $48 \%$ of the laboratories are directly related to private investment and produce healthy plants through tissue culture and micropropagation, offering a supply of about 75 million plants annually.
Research and development in other areas of biotechnology such as bioinsecticide production, inoculants, entomophagues and entomopathogens was increased. These activities, previously defined as parts of the first development stage, are able to be applied in the agriculture sector and to report short-term benefits. The number of investigations related to the study of the secondary pathway compounds of medicinal plants and their therapeutic use for further research on molecular farming also increased. These projects have promising perspectives, but they require an appropriate analytic basis and an infrastructure that should grow as on-going projects move to upper stages of development with a reliable medical validation of these products. This process requires the application of strict norms of quality control, registration and medical approval of new products for pharmaceutical use.

The range of species used in research and development projects also changed during the last decade. In 1990, 29\% of the activities were directed to fruit-bearing plants, $28 \%$ to roots and tubers, and only $1.1 \%$ to ornamental plants. In 1997 the fruit-bearing plants represented most of the activities (27\%), activities on roots and tubers decreased to $14 \%$ while in ornamental plants rose to $10 \%$. Economic reasons led to those changes. Propagation and tissue culture of fruit-bearing and ornamental plants are more profitable due to the high commercial value of the propagated plants. On the other hand, in species more important for food security, like the edible roots and tuber plants, the price of the propagated plant should go down because its actual cost is very high, limiting its access by small producers. This is a factor that affects the impact of plant biotechnology on food production seriously.

\section{Opportunities and scenarios for plant biotechnology applications}

Plant biotechnology represents one of a number of competing technological approaches to address any agronomic problem in a particular ecosystem but, as an example, a pest problem might equally be addressed through conventional plant breeding, through a transgenic approach, by the use of bio-pesticides, through an integrated crop nanagement (ICM) approach or by any combination of these.

Andean agricultural scenarios in Bolivia, Chile, Peru, Ecuador and Venezuela, for instance, are depositories of important genetic resources that could constitute inputs to food security and sustainable development. Andean "orphan" food crops such as arracacha (Arracacia xanthorrhiza), achira (Canna edulis), yacon (Polymnia sonchifolia), mashua (Tropaeolum tuberosum), oca (Oxalis tuberosa), ulluco (Ullucus tuberosus), quinoa (Chenopodium quinoa), amaranto o kiwicha (Amaranthus caudatus), popping beans -"nuñas" (Phaseolus vulgaris), tarwi (Lupinus mutabilis), goldenberry-"capuli" (Physalis peruviana), cherimoya (Annona cherimola) and passion fruit (Passiflora sp.) are highly under-utilised. The use of 
modern plant biotechnology for the conservation and sustainable agricultural use of those essential genetic resources needs to be strengthened. For this purpose, biotechnologies such as cell and tissue culture, molecular genome analysis, plant genetic ransformation, molecular plant disease diagnosis and gerplasm cryo-conservation coupled with plant breeding and physiological integrated crop management, can be successfully used to cope with genetic erosion. This can reinforce ex-situ collections and in-situ conservation, to upgrade the supply of improved and healthy seeds and planting materials for farmers and to integrate a new approach into the development programmes for food production and food security in mountain lands (Izquierdo and Roca, 1998). In the meantime, the population of the Andes suffer severely from the effects of poverty, food insecurity, malnutrition and derived health problems.

The Amazon Basin is one of the richest areas in the world. The high plant and animal biodiversity gives this area a real potential to be sustainable in terms of food security, nutrition, and economy. However, the Amazon area in all of the countries where this very special humid forest exists, has security and malnutrition problems, as well as increasing poverty, specially in areas near the biggest cities of the Amazon (Izquierdo et al. 1999). The biggest problem in the Amazon has been the colonisation path. The countries in the Amazon have a very intense migration and have been penetrated with culture systems, especially animal production, that have caused a severe impact in this very fragile bio-system. The management of Amazon soils, their poor structure, low fertility and acidity, is one of the most important subjects to be studied and this is the principal concern of several $R \& D$ institutions in the Amazon countries. The gradual conversion of the on-going "extractivism" to sustainable fruit crop-agroforestry management, where all the productivity factors are considered, requires plant biotechnology applications for fruits, vegetables ,medicinales, and forestry species including micropropagation and biotechnology-enhanced breeding

Biotechnology is a powerful tool in agricultural development with great potential - both positive and negative. Coupled with other technologies, biotechnology can surely provide new solutions for some of the old problems hindering sustainable rural development and achievement of food security (FAO, 1999; Ortiz, 1998). Biotechnology also offers unique opportunities to solve environmental problems, some of which derive from unsustainable agricultural and industrial practices.

Plant biotechnology requires both human resources ad infrastructure. The REDBIO Network has detected for this region technical constraints in terms of scarcity of human resources, limitations to technology development and use, infrastructure; institutional capacity and lack of information/data banks on plant biotechnology.

\section{Institutional support}

The development of biotechnology in the Region should be analyzed considering the real possibilities of the Region, country or among its different regions. Three categories of well-defined aspects: infrastructure, education and institutional support should be considered (Izquierdo, 1995). Infrastructure implies the establishment and assimilation of novel technologies and the implementation of material conditions according to the specific research project. This is a factor of difficult solution for the less developed countries since it implies strong investment (primary capital). Biotechnology is an emergent technological sector with the consequent economic risks. Only a strong governmental policy directed to promote this type of institutions until application and commercial use of results, will determine their gradual implementation and success for middle size projects or programmes.

The regional situation is affected by the growing activity of the transnational biotechnology companies that introduce complete technological packages with results ready for commercial exploitation. The relationship of these companies with the national biotechnology groups or programmes should contribute to the scientific development in the Region, but "clear cut" linking has to be established. Upgrading of research infrastructure, quantity and quality of trained human resources as well as appropriate norms for intellectual property rights would facilitate the implementation and financing of joint collaborative biotechnology research and development projects.

Institutional support is vital to maintain the available infrastructure, to modernise it and to maintain the qualified scientists and technicians formed during the implementation of the projects. The widespread concept on the role of institutional support limiting it to material aspect, is wrong. The institutions have the duty to assist the government in the implementation of a correct scientific policy and to define the objectives in the short, medium and long terms and, in consequence, to adequately use the available resources. They should have a scientific policy with enough flexibility to decentralise activities and functions and to allow for the creativity of the research groups according to national priorities.

\section{Perspectives for biotechnology research on food security projects in the Region}

The success of projects and activities is limited by the present basic knowledge of the different research groups on plant biotechnology. This factor determines the feasibility of achieving results in a certain term and determines the research procedure and related risks.

A second factor is closely linked with the financing possibilities that depend on the priorities stipulated by the supporting sources. Frequently, laboratories and institutions 
are particularly attracted by those projects whose end products can be rapidly marketed at a good price, such as the ornamental and fruit-bearing plants, and those that allow an amplification of infrastructure and training possibilities, such as the "winter" multiplication of GMP'seeds in joint contracts with transnational companies.

The third factor refers to the international relationships of the different groups, searching for possibilities of international co-operation through multilateral or bilateral projects. Often the biotechnology groups look for a complementation of their profiles to present international research projects according to issues that are high-priority for the agencies or companies that support international cooperation, although that priority is not necessarily such within the national and regional context. The private sector is potentially interested in applications of biotechnology but it is necessary to carefully study necessities and priorities for proposals that can offer solutions and services related to food security and sustainable production.

Worldwide, the proportion of official financial support to agricultural research has decreased from $20 \%$ of the total investment in research in 1980 to $14 \%$ in 1990 . This decreasing tendency, although smaller, continued in the late nineties. In spite of that, in the case of the LAC countries, it represents $90 \%$ of the total investment in agricultural research. In this aspect, biotechnology is still a second order addressee. However, the necessity of the producers for healthy and high genetic quality plant material, diagnosis services and certification and production of GMP seeds as well as norms related to biosafety, have increased as a consequence of the new policies in the regional economy and the efforts to look for new economic niches in the international market.

To achieve this objective the role that the public and private institutions should play to create or strengthen National Programmes to guide efforts toward the real necessities of production and food security, is important. This does not exclude the activities of advanced research laboratories or groups whose infrastructure, qualified personnel and connections with projects and programmes of developed countries allow them to develop this type of research.

Although the Region is characterised by low development in plant biotechnology, the total number of researchers under the national research systems is approximately 11000. At the present time, more than 1800 scientists, of which 1000 are postgraduates, are working in biotechnology projects within laboratories placed mainly in the universities, international research centers, and public and private institutions (REDBIO database,1999). However, due to the dispersion of the groups, faulty links with the productive sector and the absence of national and regional programs to organize and promote scientific activities, the coefficient of their real impact is considerably limited. National Programs should identify objectives and priorities in each country, in order to promote regional collaboration, find financial support and strengthen the transfer of appropriate biotechnology and biosafety norms to the producers by promoting the application of valid results.

Institutional support is reflected in all stages of scientific development, not only in research but also in the technological transfer to local producers. National institutions should promote the use of biotechnological advances for rural communities and the knowledge stemming from positive experiences to the whole system of agricultural-food production. Institutional support has been fickle in our Region and should be revitalised.

\section{References}

Asiema, J. (1994). Africa's Green Revolution. Biotechnology and Development Monitor. 19:17-18.

Bourlag, N.E. (1997). Feeding a world of 10 billion people: the miracle ahead. Plant Tissue Culture and Biotechnology 3:119.127.

Commandeur, P. (1994). REDBIO and FAO's Global Programme on Plant Biotechnology. Biotechnology and Development Monitor. 21:20-22.

FAO (1996a). Documentos técnicos de la Referencia. Cumbre Mundial sobre la Alimentación. Volumen 1:3-28

FAO (1996b). Documentos Técnicos de Referencia. Cumbre Mundial sobre la Alimentación. Volumen 1:1-3.

FAO (1996c). Documentos técnicos de referencia. Cumbre Mundial sobre la Alimentación. Volumen 2:1-22.

FAO Yearbook (1996d) Volume 50.

FAO. (1998). Regional Development Partnerships Programme (RDPP).

FAO, 1999, Committee on Agriculture: Biotechnology. 2529 January. COAG.

http://www.fao.org.unfao/bodies/coag/coag15/x00074e.htm

Garett, J. (1997). Challenges to the 2020 Vision for Latin America: Food and Agriculture Since 1970. Food, Agriculture and the Environment Discussion Paper 21. International Food Policy Research Institute. Washington D.C.

Izquierdo J., Ciampi, L. and García, E. (1995). Biotecnología apropiable: racionalidad de su desarrollo y aplicación en América Latina y el Caribe. Red de Cooperación Técnica en Biotecnología Vegetal (REDBIO). Oficina Regional FAO para América Latina y el Caribe, Santiago, Chile. 
Izquierdo, J. (1995) New Varieties for sustainable agriculture: genetic improvement assisted by biotechnology. In Seed of Conflict: Biodiversity and Food Security US Comm. World/Food Day.

Izquierdo, J. and Roca, W. (1998). Under-utilized Andean food crops: status and prospects of plant biotechnology for the conservation and sustainable agricultural use of genetic resources. Acta Horticulturae 457:157-172 [ http://www.rlc.fao.org/prior/recnat/recursos/biodiv/andinos. pdf ]

Izquierdo, J. (1999) Biotechnology can help crop production to feed and increasing world population?: positive and negative aspects need to be balanced, a perspective from FAO. Presented at International Symposium on Plant Genetic Engineering, 6-10 Dec, 1999, Cuba (in print, Elservier).

Izquierdo, J., Schejtman, A. and Figuerola. F. (1999) Heterogeneity poverty scenarios as a factor of technology demand in Latin America and the Caribbean. Presented at International workshop on research impact on poverty alleviation, San Jose, Costa Rica, CIAT, 14-16 Sept. 1999.

James, C. (1996). Agricultural Research and Development: The Need for Public-Private Sector Partnerships. Issues in Agriculture 9:1-2. CGIAR. Washington D.C.

James, C. (1997). Progressing Public-Private Sector Partnerships in International Agricultural Research and Development. ISAAA Briefs No. 4 ISAAA, Ithaca, NY. pp. 31.

James, C. 1999. Preview:global review of commercialized transgenic crops, 1999.ISAA report, No.12,

Ortiz, R. 1998. Critical role of plant biotechnology for the genetic improvement of food crops- perspective for the next millenuim. Electronic Journal of Biotechnology at http://www.ejb.ucv.cl/content/vol1/issue3/full/7/

Persley, G.J. (1997). Global Concerns and Issues in Biotechnology. HortScience 32:977-979.

Robentson, D.S (1989). Understanding the relationship between quantitative genetics. Development and Application of Molecular Markers to Problems in Plant Genetics, Helentjaris T and Burn D. (Eds). Cold Spring Habour Press.

Rosendal, K. (1992). Blue Revolution could avoid failures of green predecessor. Biotechnology and Development Monitor. 12:10.

Trigo, E.J. (1995) Agricultura Cambio Tecnológico y Medio Ambiente en América Latina: Una perspectiva para el año 2000. Documentos de Discusión sobre Alimentación, Agricultura y Medio Ambiente 9. Instituto
Internacional de Investigaciones sobre Políticas Alimentarias. Washington D.C.

Vunne, L.(1995). Biotechnology: the impact on food and nutrition in developing countries. Food Nutrition and Agriculture. 1:32-36

Woodson, W.R. (1997). Biotechnology and Horticulture, HortScience 32:1021-1023 